\title{
Feedthrough Signal Board to Cryostat Seal Design, Testing
}

\author{
Dick Applegate \\ G. T. Mulholland \\ G. Trotter
}

D0 Engineering Note

$$
\text { 3740.512-EN-245 }
$$

April 1,1990 
Signal Board to Cryostat Seal Design, Testing

page 1 of 8

\section{General}

The DO LAr calorimeters are contained in three cylindrical cryostats, symmetrical about the $X-Y$ plain drawn perpendicular to the beam ( $Z$ ) and through the middle of the center calorimeter (CC), and terminating in a north and south end calorimeters (ECN, ECS). The center calorimeter holds ca. 5,000, and each end calorimeters holds 3,000, gallons of $\operatorname{LAr}(\mathrm{BP}=\mathrm{ca}$. $90 \mathrm{~K}$ ) at a nominal pressure of $4 / 3 \mathrm{~atm}$. The 96 (32 per cryostat) multilayer, G10, signal boards map the signals from the detector to the preamplifiers, while "feeding them through" the boundary wall between the argon cryostat and the atmosphere. The feedthrough function is accomplished by attaching a hermetic flange to the signal board, and then sealing the flange to an opening in a stainless steel "signal box", an extension of the cryostat, with a bolted seal. The geometry is arranged to stratify the gas temperature in a "tower" (port) to keep the box assemblies, nominally, at room temperature.

The cryostat design must obey a set of physical constraints that, effectively, require that the circular cross-section be inscribed in a square. All warm "access ports" are constrained to reside in the upper quadrants; defined as above the equator, outside the circular cross-section, and inside the square. The small diameter ( 8 ", 6" pipe), vertical axis, ports penetrate the cylindrical, horizontal axis, cryostat shells at large (ca. 45 degree) azimuthal angles to allow a "reasonable", vertical, heat leak path for the seven (one instrumentation, two $\mathrm{HV}$, four signal) ports required. Each of these ports is "closed" by a box that serves to provide a surface for the "feedthroughs", an access panel or panels, and is itself sealed to a cryostat flange. There as many box 
seals as boxes (seven), eleven panel seals, and $(32+80+15)=127$ feedthrough assemblies providing $(32 *(1200)+80(8)+15(61))$ $=39,955$ individual feedthroughs for each cryostat.

\section{Design. Design Philosophy}

A He detector leak of significant magnitude through any of these feedthroughs is a problem to the cryostat leak check, and to the argon purity through less efficient pumping and purging. At higher levels of leakage there is a concern for the function of the cryostat as a closed, cryogenic, vessel, and, final$l y$, for the long term purity of the argon.

The individual feedthroughs are provided by weld flange (rather than "O" ring) installed, hermetic, low temperature, connectors in the case of the HV and Instrumentation boxes, and through multilayer, G10, printed circuit boards in the case of the signal feedthroughs. The individual feedthrough seals are permanent (welded, fused, or glued), small in size, have no redundancy, and are not directly monitored. They are carefully $\mathrm{He}$ leak checked at incoming inspection, at assembly, and prior to installation.

The seals that can be readily remade; the box-to-flange, panel-to-box, and signal board-to-box are; replaceable ("O" ring' indium, or "C' seal), large (to 56"), are redundant (a "warm" and a "cold" seal in each case), and are provided with an inter-seal "pump-out" manifold. They are carefully He leak checked from both sides at installation through the use of the pump-out manifold, can be "ambient side" He leak checked at any later time, and the seal (diagnostic) pump-out is continuously vacuum monitored during detector operation. 


\section{Signal Board Design Specifics}

The signal board seal design is constrained by the dimensions of the signal boards, the room available and the competition for space in each upper cryostat equipment quadrant. In addition the design addressed the board spacing and panel access to allow attachment of the signal cables from, especially, below and each side of the signal boxes. It was anticipated the boards would be mounted once, as a group. The design addressed those constraints with a rectangular, G10, flange with a race track shaped extension sealed to a mating slot in the signal box with an oneeighth inch diameter, radial, "O" ring. The cold seal is provided as an indium face seal with the usual "capture and flash" indium groove for 0.080 " diameter wire. The machined, G10, flange seal surfaces are sealed with a thin layer of epoxy in all cases.

A cryogenic test fixture was designed (drawing number; 3740.223-ME-223563) to make an actual test of sealing and nominal thermal performance of the box and some number of the boards. That test was successfully conducted with $\mathrm{LN}_{2}$ at Fermilab, and all the test equipment sent to NYU to complete the investigation in 1987.

The constraints on the problem grew to include the requirement that cables be installed from one side, or installed and cabled one board at a time. The decision not to cable from one side and a common inter-board flange clamp arrangement, required that the last installed and leak checked board must be unclamped to accommodate the installation of the next board, and so on. 
The initial attempts to install boards in the signal boxes, on the CC, in March, ' 90 were replete with difficulties. The epoxy coating on the indium flange surface was inadvertently overlooked, there were tolerance problems with board/flange assemblies, there were new indium seal installers, the welded boxes were less flat than anticipated (though readily leak checked with indium sealed Al blank-offs in fabrication), and the work had to be done in a "clean room" environment, atop the cryostat, 18' in the air.

The soluble problems were identified and appreciated, and led to an off-line testing program ${ }^{1}$. The new constraints; one side cable loading to serially installed individual boards, were accepted and the testing begun. The indium mating, lack-of-epoxy, seal surface problem was corrected almost immediately upon discovery. That, subsequently, led to the successful loading of an eight board box, with some special indium installation efforts and a higher bolt torque to deal with the lack-of-flatness problem.

The flatness was later characterized as a local, simple beam bending, no greater than 0.010 " over 11.5 ". The flange stiffness and pressure point application did not provide for deflections that large. Design changes ${ }^{2}$ that 1 ). undercut the flange by 0.200 " on each side to provide the required compliance, and 2). trimmed the clamp face to use the bolt force more efficiently, were made in a few days, and working models available in a few more days. All the testing of the current version (the clamp had one major iteration) of the design modifications indicate that they directly address and solve the problem of mating surface finishes, mating surface compliance, and the clamping and unclamping requirement. 


\section{Cold Seal Requirement}

The question of the justification for a cold seal has arisen out of the desire to find a second seal type, a warm " $O$ " ring seal, that can be installed with greater ease than the indium seals.

Each port (the argument will be limited to the signal ports) has a heat leak due to the thermal conduction of the port and the other materials that bridge the warm to cold gap. The heat leak ${ }^{3}$ of the signal port and the signal cable assembly is approximately $200 \mathrm{~W}$ in the nominal case. It is this heat leak that generates the gas that keeps the port full of gas and free of liquid. The cold seal argument can be quantified by asking what level of leak would cascade the failure of the "warm" seals, and what leak magnitude will allow the liquid to start up the port.

Note that the $200 \mathrm{~W}$ heat leak is uniformly distributed over the entire box. A seal leak would deliver up to $400 \mathrm{~W} / \mathrm{cfm}$, locally. Tests have measured a heavily bolted, warm, leakage range of $10-40 \mathrm{scfh}(0.16-0.66 \mathrm{cfm})$ for a single signal flange with it's seals removed. This factor of $>$ ten increase in local cooling will certainly make local temperature depressions, especially when the area is shielded from natural convection by a Faraday shield. The mass flow for a fixed opening at constant pressure increases as the gas cools and the density increases. This process will seek stability at some lower temperature; it doesn't fix itself, it just gets worse (colder). "O" rings have a recommended $-40 \mathrm{~F}$ minimum operating temperature. The burden of a detailed, positive, answer to this question belongs to it's proponents. If you 
can, successfully, legislate that cold leaks will never occur, "O" rings are just fine.

A gas leak of $((200 \mathrm{j} / \mathrm{s}) /(160 \mathrm{j} / \mathrm{g}))(\mathrm{cc} / 5.7 \mathrm{mg})=219 \mathrm{cc} / \mathrm{s}=$ $0.46 \mathrm{cfm}$, will just equal the local heat of vaporization gas generation by the nominal heat leak. Note, however, that the sensible heat of that flow is (or quickly becomes) the source of another ca. $(1.27 \mathrm{j} / \mathrm{gK})(200 \mathrm{~K})(1.25 \mathrm{~g} / \mathrm{s})=318 \mathrm{~W}$ of cooling. That will locally cool the leak area just as in the above illustration, and with the same result; lower temperatures and increased flow.

When the flow out of the port exceeds that nominally generated by heat leak the port liquid level wants to rise. If liquid rises in the port, it must rise through half of the heat leak path to double the gas load, half the remaining path to double it again, and so on. The rise of the liquid in the port is mitigated by increased gas generation, if there is a limiting gas flow at some temperature. If the flow area increases as the temperatures falls the temperature will continue to fall toward the source temperature. If all eight "warm" seals were to fail to the mean of the "warm" leakage test value, the gas flow is the equivalent of $1.3 \mathrm{~kW}$, and more when cold.

But if it never happens, why should we care? The probability that one of the 96 , carefully installed, sets of signal board "O" rings leak through is hard to predict in detail. There are published failure rates for more ideal installations, but none for this application, or with temperature applications beyond recommendations on an unconnected fault. It should be clear, however;

1). These seals are, by far, the weakest point in the Argon 
containment system. They will determine the Argon containment system reliability.

2). The radial, G10, race track, "O" ring is, considering asbuilt tolerances and type, not a high reliability installation.

3). It is not good practice to seal potential cold leakers, especially remote, inaccessible, cold leakers, with warm seals and without a viable contingency plan. Who will do the required "Failure","What if" and "Hazard" analysis?

4). Replacement of the "improved" indium cold seal with the warm "O" ring seal will significantly reduce the fault tolerance of the installation in this service. 
Signal Board to Cryostat Seal Design, Testing

page 8 of 8

\section{References:}

1. Indtest; the indium test file, attached

2. Signal Board sketch showing undercut, smart clamp cross-section, attached

3. Cryostat heat leak, attached 
INDTEST, $3 / 22 / 90$, corrected and appended $3 / 27 / 90,3 / 28 / 90,3 / 30 / 90$, and

Test \#1. Location EBT.

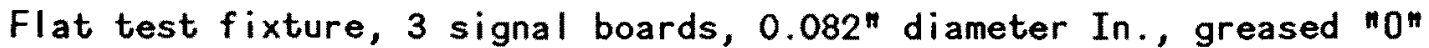
ring, and pump on the PO. (Uncoated G10 flange surface)

RESULTS; The slot had an "0" ring finish problem that was successfully addressed by heavily greasing the "on ring. The indium did not seal and had a patterned, dull appearance.

Test \#2. Location EBT.

Same as Test 1 . with the G10 flange surface coated with Kinseal vacuum sealer.

RESULTS; All 3 boards sealed with a torque of 30 in. Ibs.. Flash was thinner on each end of the race track and traced to a 610 flange flatness problem. The boards were 0.008 to 0.012 inches out of $\mathrm{flat}$ on the ends, and machined flat in the High Rise machine shop (arranged by Kotcher, Sculli, machined by Lee Simpson).

Test \#3. Location EBT.

Same as Test 1 , with the newly (uncoated) machined flanges.

RESULTS; All boards did not seal. All 9 boards were thinly coated with epoxy and cured for 12 hours at 160F.

Test \#4. Location EBT.

Same as Test 3 with thin epoxy coat on the G10 flange.

RESULTS; Had some incidental trouble with the "an rings, but overcame that. Three angle cut In. spliced boards sealed at 30-35 in. Ibs. torque. Six square cut In. splice, In. seal, boards sealed at 30-50 in. Ibs. torque.

Test \#5. Location NE signal box O CC in DO.

Eight boards installed in series to a $10 \mathrm{in.}$ Ibs. torque with cables attached as the boards were installed.

RESULTS; There were two leaks; location \#1 and between board \#3 and \#4. Location \#1 was fixed by shimming the In. and the clamping bar by $0.010^{n}$. The leak between \#3 and \#4 was 30 divisions ( 6 on the 5 scale), on a He leak detector. The assembly was retested a few days later and found to be He Leak tight.

Test \#6.

Three lightly coated epoxy boards for minimum seal torque.

$\begin{array}{rlll}\text { RESULTS; } & \text { 2nd } & \text { 3rd } & \text { 4th } \\ \text { Board \#1 } & 30 & 30 & 30 \\ \text { Board \#2 } & 35 & 45 & 30 \\ \text { Board \#3 } & 40 & 30 & 45 \text { in. Ibs. }\end{array}$

Note; The third test included torquing to seal, and unclamping and retorquing to seal. The flange resealed at the same torque. 
Test \#7.

Test three flat teflon gaskets.

RESULTS; All three leaked badly at the ends.

Test \#8.

Coating investigation.

RESULTS; Thin coats seem to apply best by wiping with a Kimwipe to remove the excess epoxy.

Casting epoxy between the flange and a mylar sheet leaves a very smooth surface, but the technique needs to be improved to repeatedly produce a uniform and continous, surface.

A Cu clad, $10 \mathrm{mil}$ G10 board was epoxy laminated to the G10 flange. The board leaked at the epoxy joint. The application technique needs to be developed and improved.

Kimseal is easy to apply and dries quickly, but is easily removed by solvents. Alcohol, for instance, does a good job of disturbing the surface.

Polyurethane sprays (clear satin finish, and varnish) coat well, but were not included in the test program for reasons of time.

Test \#9. Location DO SW signal box now in EBT.

Test the flash of the Al blank-off plates.

RESULTS; Flashed widely and uniformly.

Test \#10. Location DO SW signal box now in EBT.

He leak test eight thinly coated flanges.

RESULTS;

$\begin{array}{lllllllll}\text { Position } & 1 & 2 & 3 & 4 & 5 & 6 & 7 & 8 \\ \text { Torque (in \#) } & 50 & 50 & 75 & 55 & 35 & 35 & 35 & 35\end{array}$

Note; Flashing was better (wider) at the ends, confirming the boxes dip in the center, especially in the end slots (i.e. number 1 and 8 ).

Test $\$ 11$. Location DO SH signal box now in EBT.

Make up $4 \mathrm{flange,} \mathrm{dummy} \mathrm{board,} \mathrm{test} \mathrm{pieces.} \mathrm{Undercut} \mathrm{three} \mathrm{flanges} \mathrm{by}$ $0.190-0.200$ inches and $\mathrm{clad}$ one with a $0.015 \mathrm{mil}$ SS sheet.

Test the compliance to the top plate of the 3 , new, slotted, flanges.

RESULTS; Clearance measured at two notches in the end clamp bar (ca. $+/-3 / 4^{\prime \prime}$ about the centerline).

$\begin{array}{lcc}\text { Location } & A \text { end } & B \text { end } \\ \text { resting on the box } & 0.010^{n} & 0.002^{n} \\ 20 \mathrm{in.} \mathrm{\#} & 0.002^{n} & 0.003^{n} \\ 30 \mathrm{in} . \# & <0.0015^{n} & <0.0015^{n}\end{array}$


Test \#12. Location DO SW signal box now in EBT. boards.

He leak test the sealing of the three new, untreated surface, slotted,

RESULT; All leaked (how bad?) at 100 in. \#torque. Untreated surfaces are not a solution.

Test \#13, Location DO SW signal box now in EBT.

Test SS steel clad, no slot, flange and board in slot \#1, and Kinseal/ undercut flange and board in slot \#8.

RESULTS; The boards were He leak tight sealed at the torques indicated.

$\begin{array}{ll}\text { SS Clad } & \text { Sealing torque } \\ \text { Kinseal/undercut } & 20 \mathrm{in.} \mathrm{\#} \\ & 30 \mathrm{in} . \#\end{array}$

Test \#14. Location DO SW signal box now in EBT.

He leak test a Kimseal/slotted flange seal by clamping and unclamping. RESULTS;

$\begin{array}{cc}\text { SS bolt torque } & \text { On } \\ 60 \mathrm{in.} \# & \text { OK } \\ 80 \mathrm{in.} & \text { OK } \\ & \\ \text { Carbon Steel bolt torque } & \\ 100 \mathrm{in} . \# & \text { OK } \\ 120 \mathrm{in} . \# & \text { OK } \\ 140 \mathrm{In} . \# & \text { OK }\end{array}$

Special Test. Location "0" ring test fixture.

A dummy board that had been immersed in liquid nitrogen showed crazed epoxy surfaces at the flange to board joint. The damage was cause for concern for the tightness of the seal.

RESULTS; He Leak testing demonstrated the epoxy seal from top flange to board had a large leak to the PO volume, a much smaller leak existed between the Argon and air sides (i.e. through the flange), and a leak exists between the SS shim and the G10 to the PO.

Test \#15. Location DO SW signal box now in EBT.

Test.

Clean up and thin epoxy coat the slotted flange surfaces and perform a "leap frog" test with three boards. Fill slots 1,2, and 3 , He leak tight and unclamp and move \#1 to the slot 4 , reclamp, and He leak test. Repeat with the \#2 board in the slot 5, and so on, He leak checking the clamping and unclamping at each change. Record the torques necessary to reclamp in each case.

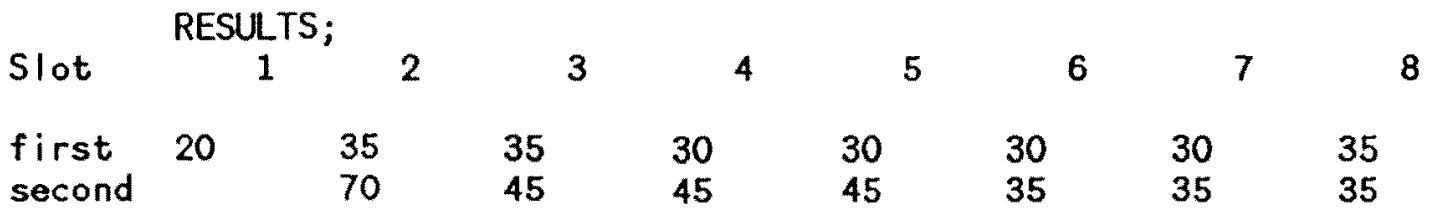


Where all bolt torques are in in. Ibs.. One torque at the second sealing provided some concern (i.e. second, $1-2,=70$ in. lbs.).

Note: The board in the 3 and than the 6 slot was a standard signal board (i.e. not undercut).

Test \#16. Location DO SW Box now in the EBT.

Test the Special Test board that failed at the glue joint for structural integrity. Shim the flange ends by $0.030^{\mathrm{n}}$ at each end and load with the clamp bar to 50 in. \#.

RESULTS; No motion of the flange relative the board. The conclusion; to this level of load there is "no structural problem.

Test \#17. Location DO SW box now in the EBT.

Test the flow of indium against a $G 10 \mathrm{flange}$ as a $F\{t\}$. Load a $f$ lange with new Indium and torque bolt clmps to $50 \mathrm{in. \# .} \mathrm{Data} \mathrm{follows,}$

RESULTS;

$\begin{array}{llll}\text { Day } & \text { Time } & \text { North end } & \text { South end } \\ 3 / 26 / 90 & 1447 & 0.000 & 0.000 \\ & 1453 & 0.0005 & 0.000 \\ & 1510 & 0.001 & 0.000+ \\ & 1540 & 0.0013 & 0.001 \\ 3 / 28 / 90 & 1600 & 0.0014 & 0.001+ \\ & 0730 & 0.0024 & 0.002\end{array}$

Retorqued to 50 in.\#.

0735 Flat to box 0.002

The indium flows $0.002+\mathrm{mils}$. and stops at $50 \mathrm{in}$.\#. All data taken in the same day should provide poorer seal testing results than could be expected long term. Similar results have been experienced with Indium with other flange materials, i.e. it thought to be an indium, and not a $\mathrm{G10}$, characteristic.

Test \$18. Location DO SW box now in EBT.

Test the leakage by one $f$ lange $W / 0$ seals in one slot, with the other slots plugged with sealed blanks. Smart bars were used in the test slot \#8.

RESULTS;

Note: 1). The signal box volume is ca. $1.3 \mathrm{cf}$.

2 ). The flow are measured at the inlet pressure (scales as the square root of the density; the absolute pressure).

Signal Board at 40 in\# torque.

Time Interval

$25 \mathrm{sec}$. interval

$P$

24.6

16.4 psia

Signal Board at $80 \mathrm{in. \# .} \mathrm{(flowmeter} 86 \mathrm{cfh}$ at $29.6 \mathrm{psia}$ )

$15 \mathrm{sec}$. intervals 29.6 
Slotted Flange Model Board at 40 in.\#. (82 cfh at 29.7 psia) $15 \mathrm{sec}$. intervals 29.7

25.0

22.3

20.6

19.2

18.0

17.0

16.4 psia

Slotted Flange Model Board at 80 in. (18 $\mathrm{cfh}$ at $29.8 \mathrm{psia}$ )

$30 \mathrm{sec}$. intervals 29.8

28.2

27.0

25.9

24.9

24.1

23.3

22.5

21.9

20.7

psia

Aluminum Blank-off at $40 \mathrm{in. \# .} \mathrm{(40cfh} \mathrm{at} 29.7 \mathrm{psia})$

$30 \mathrm{sec}$. Intervals 29.4

26.2

24.0

22.3

21.0

20.0

19.0

18.2

17.6

17.1

psia

Aluminum Blank-off at $80 \mathrm{in. \# .} \mathrm{(less} \mathrm{than} 8 \mathrm{cfh}$ at $29.7 \mathrm{psia}$ ) $30 \mathrm{sec}$. Intervals 29.7

29.4

29.1

28.9

28.7

28.5

28.4

28.3

28.1

28.0

27.8

psia

Conclusion

The Al blank seals the best because it has the best surface and conforms most readily. The generic signal board and the slotted flange model board have the same surfaces and their flow differences (ca. 5) are attributable to differences in their compliance to the surface.

END 


\section{Signal Boards}

Nominal

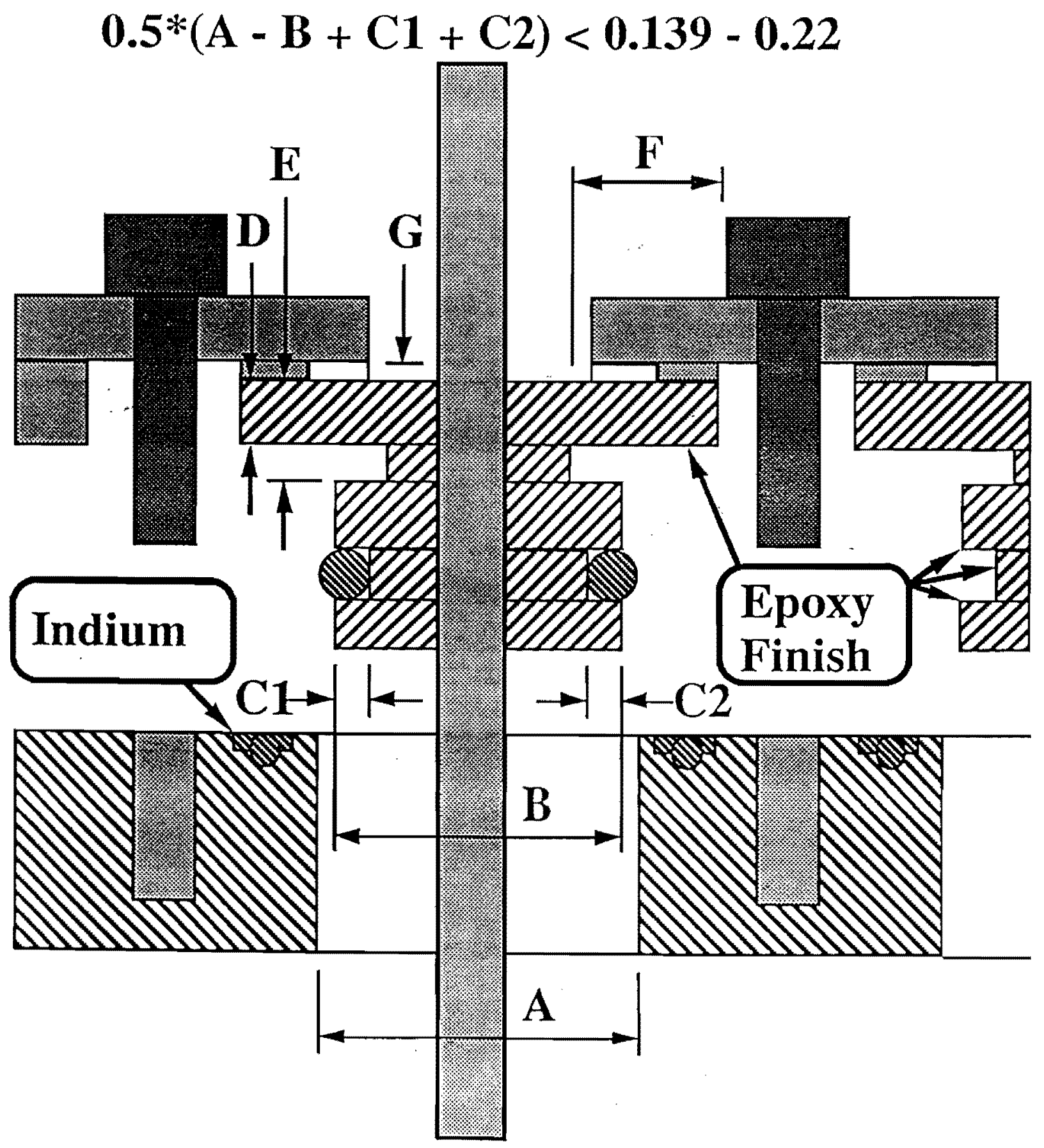




\section{Cryostat Workshop \\ CC Cryostat, watts}

Item, number

Signal Coax ${ }^{1}, 4 *(192 * 25)$

Instr. Wire ${ }^{2},(14 * 61)$

HV cables ${ }^{3}, 2 *(40 * 8)$
Above Below

Equator Equator

4(160)

40

$\underline{21}$

701

$\overline{0.0} \quad 701$
Signal Ports 4,4

Instr. Port ${ }^{5}, 1$

HV port ${ }^{6}, 2$

All piping

Thermal siphon
4(12)

6

2(11.5)

5

1.5

$\underline{4(36)}$

$\overline{226} \cdot \overline{1.5} \quad 227.5$

Radiation

MR Beam tube ${ }^{7}$

Center cylinder ${ }^{8}$

All other ${ }^{9}$
3

8.5

$\underline{75}$

86.5
8.5

$\underline{75}$

$83.5 \quad 170$

Supports ${ }^{10}, 4$

$4(4)$

Totals

$\overline{1013.5} \quad \overline{101} \quad 11 \overline{14.5}$

Notes: (1/4/89 update, adds thermal siphon load, corrects 10$)$ )

1) Coax, AWG 28, 2) Tefzel AWG 22, 3) 7/32,4) 8"ips sch 10, 5) 6"ips sch 10, 6) 4" ips sch 10,7) warm dia. =9", 8) warm dia. $\left.=59^{\prime \prime}, 9\right)$ cryostat dia. $=204$, length $\left.=120^{\prime \prime}, 10\right) 365$ tons total 